\title{
COMPORTAMENTO DO FLUXO DE ENERGIA EM EVENTOS DE GEADA
}

\author{
Débora Regina Roberti, Douglas Carmo De Avila, Lucas Augusto Fagundes, Hans Rogério \\ Zimmermann
}

Universidade Federal de Santa Maria, Santa Maria, RS

\section{RESUMO}

Geada ocorre quando a temperatura da superfície chega abaixo de $0^{\circ} \mathrm{C}$. Esta superfície pode ser a nível do solo ou das plantas. O fenômeno da geada pode ocorrer por processos radiativos ou advectivos. Neste trabalho, as componentes do fluxo de energia foram analisadas em condições favoráveis para ocorrência de geada no sul do Brasil. Nestes eventos, o fluxo de calor do solo para a superfície é dominante enquanto o fluxo de calor latente e sensível são praticamente zero.

\section{ABSTRACT}

Frost occurs when the surface temperature falls below $0^{\circ} \mathrm{C}$. This surface can be the ground level or plants. The phenomenon of frost can occur by advective or radiative processes. In this work, the components of the energy flux were analyzed in conditions favorable for the occurrence of frost in southern Brazil. In this event, the heat flux to the surface of the soil is dominant as the latent and sensible heat fluxes are practically zero.

\section{INTRODUÇÃO}

Quando a temperatura do ar próximo a superfície chega ao ponto de congelamento da água pode ocorrer o fenômeno conhecido como geada. Ela ocorre quando o vapor de água existente no ar, ao cair da noite, transforma-se em cristais de gelo. Estes cristais de gelo costumam cobrir a vegetação, podendo, assim, dificultar o desenvolvimento das plantas, pois a seiva das mesmas pode congelar, impossibilitando o funcionamento das células vegetais.

Eventos de geada podem ocorrer devido ao resfriamento radiativo em noites de céu claro e ventos fracos, ou na forma de advecção de ar frio para um local acompanhado de ventos fortes (Oke, 1987). Assim, pode ocorrer geada por processos radiativos ou advectivos. Neste trabalho, analisaremos o comportamento das componentes do balanço de energia em eventos propícios a formação de geada no sul do Brasil.

\section{METODOLOGIA}


Os dados utilizados foram coletados por uma torre de fluxo numa área de cultivo agrícola no município de Cruz Alta - RS (28³6'S, 5340'O), no período de 21/07/2009 a 30/07/2009. Os seguintes sensores foram utilizados (altura do sensor na torre, fabricante, modelo) na frequência de 10Hz: Temperatura do ar (2,5 m; Campbell Scientific - CSAT 3); Componentes do vento (2,5m; Campbell Scientific - CSAT 3), analisador de gás H2O/CO2 gas analyser (2,5 m; LiCor, LI7500), fluxo de calor no solo (-2 cm, Hukseflux, HFP01SCL); precipitação (1.5 m, Texas Instruments). Os dados de fluxo de energia foram processados pela técnica de covariância dos vórtices (Baldocchi et al., 1988) em médias de 30min. Dados espúrios de fluxos não foram corrigidos.

Para descrever os eventos de geada, foi utilizada a condição de temperatura do ar a $2,5 \mathrm{~m}$ de altura menor que $2^{\circ} \mathrm{C}$.

\section{RESULTADOS}

O mês de julho de 2009 teve vários dias com condições para a formação de geada na região de Cruz Alta-RS. A figura 1 apresenta o ciclo diurno, no período de 21/07/2009 a 30/07/2009, das variáveis atmosféricas (temperatura, velocidade do vento e precipitação) e das componentes do balanço de energia: H, fluxo de calor latente, LE, fluxo de calor no solo, $\mathrm{G}$ e saldo de radiação, Rn. Formação de geada, conforme a condição de temperatura menor que $2^{\circ} \mathrm{C}$ a 2,5m de altura foi satisfeita nas madrugadas dos dias 24, 25 e 26 (área hachurada da Figura 1). Nestes dias foi observada visualmente geada que acarretou na morte da aveia que estava na fase de emergência.

Nestes eventos, a formação da geada pode ser considerada como um processo radiativo, já que a velocidade do vento foi muito baixa, abaixo de $1 \mathrm{~m} / \mathrm{s}$, e a perda radiativa foi intensa, conforme dados de Rn. Tanto os fluxos de calor latente quanto sensível foram praticamente nulos nos horários da formação da geada. O fluxo de calor no solo foi dominante e com valor mais negativo que nos dias 28 e 29, por exemplo, quando a condição de geada não é satisfeita. Na madrugada do dia 30, a temperatura foi próxima a $2^{\circ} \mathrm{C}$, e as componentes do balanço de energia apresentaram o mesmo comportamento do dias 24,25 e 26. Nas noites do dia 22 e 26, devido à precipitação e a muito baixa velocidade do vento, respectivamente, os fluxos de calor latente e sensível apresentaram valores que podem ser considerados espúrios.

\section{CONCLUSÃO}


A ocorrência de geada no sul do Brasil em julho de 2009 ocorreu devido aos processos radiativos, em situações de vento fraco. Nestes eventos, o fluxo de calor do solo para a superfície é dominante, enquanto o fluxo de calor latente e sensível é praticamente nulo.
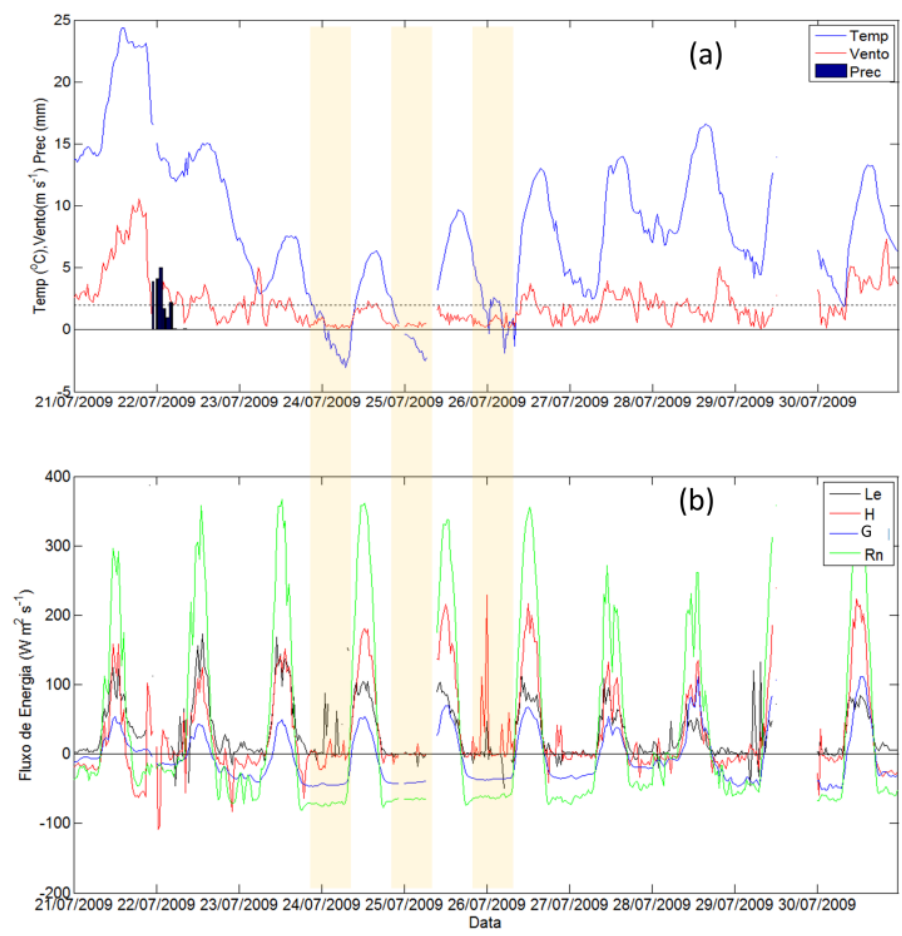

Figura 1. Ciclo diurno da (a) temperatura, velocidade e precipitação e (b) dos componentes do balanço de energia (Le, H, G, Rn) no período de 21 a 30/07/2009. A linha pontilhada em (a) representa a temperatura de $2^{\circ} \mathrm{C}$.

\section{REFERÊNCIA BIBLIOGRÁFICA}

Baldocchi, D.D.; Hicks, B.B; Meyers, T.P. Measuring biosphere - atmosphere exchanges of biologically related gases with micrometeorological methods. Ecology, 69 (5), 1331-1340. 1988.

Oke, T.R. Boundary Layer Climates, 2nd Edition. London: Routledge, 1987. 